\title{
Política social compensatoria y justicia general
}

\author{
Édgar Antonio Guarín Ramírez" \\ Laura Galeano Gómez** \\ Valentina Galindo Sánchez"***
}

Recibido 18 de septiembre del 2018

Evaluado: 30 de octubre de 2018

Aceptado: 23 de noviembre del 2018

Citar como: Guarín Ramírez, É. A., Galeano Gómez, L. y Galindo Sánchez, V. (2019). Política social compensatoria y justicia general. Hallazgos, 16(32), 43-61. DOl: https://doi. org/10.15332/2422409X.5092

\section{RESUMEN}

Este artículo de reflexión es resultado de un proyecto de investigación que tuvo como objetivo analizar las consecuencias que tiene para la justicia general la manera como, actualmente, se implementa la política social en Colombia. En desarrollo de esa política, el Estado hace suya la obligación de suplir las necesidades básicas de los sectores menos favorecidos mediante la entrega de bienes y servicios. La hipótesis planteada es que dicha manera de adelantar la política social, cuando consume al destinatario en su situación de marginalidad y pobreza, le sustrae de sus obligaciones para con el todo social, lo cual afecta la justicia general. En virtud de este tipo de justicia, los miembros de la comunidad tienen la obligación de contribuir al bien del todo social, desde sus capacidades y posibilidades; si ello no se da, surge una forma de injusticia que tiene importantes repercusiones para la construcción del tejido social.

Palabras clave: política social compensatoria, justicia general, bien común.

\footnotetext{
Doctor en Derecho, magíster en Derecho Público, especialista en Derecho Penal, Derecho Administrativo y Docencia Universitaria. Director del semillero de investigación en Filosofía y Teoría del Derecho de la Facultad de Derecho de la Universidad Santo Tomás, Bogotá D. C., Colombia. Investigador asociado Colciencias. Miembro del grupo de investigación Raimundo de Peñafort. Correo electrónico: edgarguarin@usantotomas.edu. CO - ORCID: https://orcid.org/0000-0002-3329-1591.

* Integrante del semillero en Filosofía y Teoría del Derecho de la Facultad de Derecho de la Universidad Santo Tomás, Bogotá D. C., Colombia. Miembro del grupo de investigación Raimundo de Peñafort. Correo electrónico: lauragaleano@usantotomas.edu.co - ORCID: https://orcid. org/0000-0002-2717-4831.

*** Integrante del semillero en Filosofía y Teoría del Derecho de la Facultad de Derecho de la Universidad Santo Tomás, Bogotá D. C., Colombia. Miembro del grupo de investigación Raimundo de Peñafort. Correo electrónico: valentinagalindo@usantotomas.edu.co - ORCID: https://orcid. org/0000-0002-3523-0493.
} 


\title{
Compensatory social policy and general justice
}

\begin{abstract}
This reflection article is the result of a research project that aimed to analyze the consequences for the general justice of the way in which, currently, social policy is implemented in Colombia. In development of that policy, the State endorses the obligation to supply the basic needs of the less favored sectors through the delivery of goods and services. The hypothesis proposed is that this way of conducting social policy, when it consumes the recipient in his situation of marginality and poverty, removes him from his obligations to the social whole, which affects general justice. By virtue of this type of justice, the members of the community have the obligation to contribute to the good of the social whole, from their capacities and possibilities; if this does not happen, a form of injustice arises that has important repercussions for the construction of the social tissue.
\end{abstract} Received: september 18, 2018 Evaluated: october 30, 2018 Accepted: november 23, 2018

Keywords: Compensatory social policy, general justice, common good. 


\section{Política social compensatória e justiça geral}

Recebido: 18 de setembro de 2018

Avaliado: 30 de outubro de 2018

Aceito: 23 de novembro de 2018

\section{Resumo}

Este artigo de reflexão é resultado de um projeto de pesquisa que teve como objetivo analisar as consequências que tem para a justiça geral a maneira, como, atualmente, implementa-se a política social na Colômbia. No desenvolvimento dessa política, o Estado faz sua a obrigação de suprir as necessidades básicas dos setores menos favorecidos mediante a entrega de bens e serviços. A hipótese apresentada é que esta maneira de adiantar a política social, quando consome ao destinatário na sua situação de marginalidade e pobreza, lhe subtrai de suas obrigações para com o todo social, o qual afeta a justiça geral. Em virtude deste tipo de justiça, os membros da comunidade têm a obrigação de contribuir ao bem do todo social, desde suas capacidades e possibilidade; se isso não acontecer, surge uma forma de injustiça que tem importantes repercussões para a construção do tecido social.

Palavras-chave: política social compensatória, justiça geral, bem comum. 


\section{INTRODUCCIÓN}

Este artículo es resultado de un proyecto de investigación que se propuso analizar la problemática actual respecto de las consecuencias que tiene para la justicia general la manera como se está implementación en Colombia la política social. En desarrollo de ella, el Estado asume la responsabilidad frente a la injusticia estructural que vive el país y que afecta a los sectores menos favorecidos, de tal forma, que hace suya la obligación de suplir las necesidades materiales básicas de ciertos grupos poblacionales; por esta razón, este modus operandi en materia de política social ha sido denominado "compensatorio". La cuestión ha sido abordada y justificada ampliamente desde la perspectiva de la denominada justicia distributiva, esto es, aquella forma de realizar el derecho en la cual el Estado tiene una obligación jurídica para con sus asociados de velar porque tengan lo necesario para vivir dignamente. Empero, el análisis de este tipo de política social desde la justicia general, es decir, desde lo que los particulares deben al todo social, está aún en ciernes. Este artículo busca hacer un aporte a la cuestión desde esta última perspectiva.

El Estado colombiano, en cuanto social, democrático y de derecho, tiene como parte de sus políticas públicas subsidiar a quienes tienen necesidades especiales dentro de la comunidad política con el fin de que puedan alcanzar la suficiencia de bienes que requieren para vivir bien. Para ello, viene adelantando, especialmente desde las últimas décadas, un tipo de política social que atiende a la población más vulnerable, a la que considera víctima de unas políticas económicas avaladas por el Estado con un marcado acento capitalista, y que ha marginado a muchos ciudadanos llevándolos a situaciones de pobreza extrema. Esta manera de proceder, analizada a la luz del concepto de justicia distributiva, es loable en el entendido de que esas personas tienen el derecho de ser asistidas por el Estado sobre quien recae una deuda de justicia para con sus asociados.

Sin embargo, el problema surge cuando, en ese asumir la responsabilidad de la injusticia social, el Estado entrega bienes y servicios a ciertos sectores de la población sin que exista una planeación bien estructurada y sin medir suficientemente los efectos que este modo de actuar tiene para la vida de las personas y para el todo social (Alvarado-Chacín, 2003). Como afirma González Bonilla (2006), la entrega de subsidios es, en realidad, un paliativo que permite quizás atenuar la pobreza, pero no resolverla; al contrario, no en pocas ocasiones, la perpetúa y hace que las personas se acostumbren a vivir de la caridad pública.

Lo distintivo de la política pública bien estructurada es el hecho de integrar un conjunto de acciones ordenadas, estables y sistemáticas, que representan el modo en el que el Gobierno realiza de manera permanente y estable las funciones públicas y atiende los problemas públicos. Dicho de otra manera, lo específico y peculiar de la política pública consiste en ser un conjunto de acciones intencionales y causales, orientadas a la realización de un objetivo de interés público, cuyos lineamientos de acción, agentes, instrumentos, procedimientos y recursos se reproducen en el tiempo de manera constante y coherente (Aguilar Villanueva, 2012). 
La ausencia de una política pública con estas características, da lugar a una forma de injusticia en la que el sujeto pasivo ya no es un particular o un sector poblacional en concreto, sino la comunidad políticamente organizada que tiene como derecho propio el que cada uno de sus miembros contribuya a la vida comunitaria. Dado que la justicia es el concepto que de manera más acabada expresa lo propio de la experiencia social, lo cual puede ser contrastado históricamente desde la antigüedad hasta el presente, es particularmente importante reflexionar sobre las consecuencias que, para la justicia general, se derivan de la implementación de una política social de carácter compensatorio. De esto se ocupan estas líneas.

\section{Política social en Colombia: PROBLEMÁtica}

Las políticas sociales, para ser exitosas, están llamadas a mirar más allá de la asignación y entrega de bienes y servicios. Ese "mirar más allá" implica, por ejemplo, revisar su estabilidad y eficiencia. La estabilidad y la eficiencia están más relacionadas con la denominada justicia general por cuanto, una y otra, buscan garantizar la armonía social y la permanencia del Estado, a la cual todos los asociados deben contribuir. Cuando en desarrollo de la política social se adelantan programas que no son estables y eficientes, en el sentido de contribuir realmente a la superación del estado de pobreza en que los destinatarios se encuentran, ella se convierte en un foco de injusticia porque afecta al todo social.

Actualmente, la política social que se desarrolla en Colombia no se caracteriza por dicha estabilidad y eficiencia. Refiriéndose a los problemas administrativos de los programas de carácter social que existen actualmente en el país, que son calificados como compensatorios, escribe González Bonilla (2006):

Los subsidios más importantes de carácter corriente se dan en el régimen subsidiado de salud, en el otorgamiento de cupos escolares con alguna ayuda alimenticia y en útiles escolares, la menor tarifa con servicios públicos, los auxilios a la tercera edad y el aporte para la adquisición de vivienda de interés social, entre otros. No es una estrategia nueva, está amparada en las decisiones de la Constitución de 1991 y se deberían entregar a personas y familias identificadas por la encuesta Sisbén en niveles 1 y 2; desafortunadamente, la realidad es diferente y muchos subsidios son recibidos por personas y hogares que no los necesitan.

La Asociación Nacional de Instituciones Financieras, ANIF, estableció en 2017 que el Sistema de Selección de Beneficiarios para Programas Sociales (Sisbén), que es el principal instrumento de focalización individual para luchar contra la pobreza en Colombia y que es utilizado por entidades como el ICBF, el Sena, el Icetex, los ministerios de Salud y de la Protección Social, Educación Nacional, Agricultura y Desarrollo Rural, y Trabajo, así como el Ejército Nacional para otorgar beneficios a las personas que reportan mayores necesidades (DNP, 2017), tenía para ese año 35800785 personas registradas en todo el país pero en realidad, en el total nacional, 12883000 personas se encontraban en situación de pobreza monetaria $(26.9 \%)$, y alrededor de 4 millones de personas se hallaban en situación de pobreza 
extrema; el DNP tan solo detectó 400000 casos de inconsistencias frente a cerca de 20 millones de personas que no deberían estar en el Sisbén (ANIF, Clavijo y Londoño, 2017). Así, según el DPN, las personas con ingresos mensuales mayores a \$3.8 millones con puntajes menores a 50, inscritas en el Sisbén, son 135 756; y el número de personas fallecidas y que se encuentran registradas es de 161 594; los casos de quienes tenían inconsistencias en la información de su vivienda, pues reportaban vivir en un cuarto, pero en realidad lo hacían en una casa, es de 62 529, así como la variable de "cambios no justificados", que incluye a quienes disminuyen de manera irregular su grado de escolaridad o cambian su casa de zona urbana a rural sin modificar la dirección, es de 24703 (DNP, 2016).

De otra parte, la masificación del régimen subsidiado de salud y de programas como Familias en Acción, les ha dado a muchos trabajadores informales de los niveles $1 \mathrm{y}$ 2 del Sisbén un incentivo perfecto para no formalizar su trabajo. ¿Para qué querría un trabajador informal tener una vinculación con un salario mínimo, que le obliga a cotizar salud y pensión cuando puede obtener salud subsidiada y además recibir ayudas en efectivo? (Ronderos, 2010). Esta situación genera conflictos sociales porque las personas que trabajan y contribuyen con el pago de sus impuestos al bien de todos, se sienten inconformes y afectadas en sus derechos cuando ven que hay individuos que viven con total dependencia del Estado, constatando que muchos de ellos tienen las posibilidades y capacidades para trabajar y contribuir, con ello, al bien del todo social. Surge entonces el conflicto como resultado de la injusticia que ello acarrea.
La política social en Colombia parece estar generando una cultura asistencialista, esto es, "una política de sujeción, no una política de promoción de la persona humana, en donde el hombre sea gestor y sujeto de su propio desarrollo" (Casas Ortiz, 2014). Se genera con ello, una dependencia por parte de algunos sectores poblaciones, que es terreno abonado para la aparición de mesianismos políticos que no están interesados en ayudar a superar la mentalidad y costumbre de recibir las cosas con el mínimo esfuerzo (Huertas, 2018). En este sentido, la Organización para la Cooperación y el Desarrollo Económicos (OCDE) en el documento "Extendiendo oportunidades. Cómo activar la política social en beneficio de todos", establece que:

Los programas de combate a la pobreza con tintes asistencialistas crean vacíos y generan mayor pobreza y segregación [...] ya que para reducir el número de pobres se requiere de potenciar el mercado laboral y dejar de lado los instrumentos que no están "bien dirigidos", porque crean mayor marginalidad entre sus beneficiarios. (Muñoz, 2005).

El trabajo dignifica y hace sentir bien porque uno ha creado algo con sus manos, gracias a su capacidad y talento. Por eso, cuando se reparten bienes y servicios sin medida, en lugar de abrir posibilidades laborales, se crea una dependencia de esa ayuda que no es respetuosa del ser humano. Así entonces,

[...] cualquier proceso de estos termina siendo insuficiente porque las personas que recibieron el beneficio del asistencialismo, al poco tiempo están igual o peor, pero con resentimiento, 
dependencia e impotencia. Vamos a la lógica, "si me dan, ¿para qué hago?", ese es el modo de pensar que generan los enfoques asistencialistas. Los riesgos de estos modelos son que blindan contra el deseo de superación, contra las ganas de trabajar. El asistencialismo institucional, hace que ser pobre sea más atractivo y eso genera una resistencia al desarrollo económico. (Huertas, 2018).

"Hay que ayudar, pero no asistir" (Rubin, 2018).

Los programas caracterizados por el asistencialismo asumen que las personas necesitan de la asistencia para vivir mejor. "Se trata a los receptores como objetos pasivos, incapaces de participar en el proceso de su propia recuperación. El mayor problema es el antidiálogo; en donde la imposición del silencio y la pasividad niegan que las personas puedan desarrollarse" (Franco Martínez, 2011). La política social en Colombia no ha logrado equilibrar el apoyo con el emprendimiento; la ayuda con la inversión de recursos,

[...] para enseñar a las personas a crear sus empresas y administrarlas sin depender para siempre del auxilio del Estado, situación que genera una dependencia a los presupuestos públicos, al facilismo, al conformismo, inclusive al caudillismo y que no contribuye al crecimiento ni personal ni económico de nuestros habitantes. (Huertas, 2018).

La cuestión es, entonces, que más allá de este tipo de problemas administrativos que se evidencian en la política social que ha tenido lugar en Colombia actualmente y que están referidos a la falta de estructuración, a la ausencia de un sistema claro de graduación de los programas, al desvío de recursos, al ofrecimiento de estos subsidios a personas que no necesariamente tienen los índices más altos de necesidades básicas insatisfechas (NBI) (Cortés, 2010), este tipo de política social no contribuye a la superación de la pobreza -finalidad a la que debería tender- sino que hace que las personas se perpetúen en ella, con lo cual, también se prolonga en el tiempo su situación de marginación social y de dependencia, convirtiéndose en un campo propicio para la germinación del clientelismo y la corrupción; no son, por tanto, políticas integrales que rompan las trampas de la pobreza, teniendo en cuenta a los pobres como actores indispensables dentro del proceso y aprovechando sus capacidades para que ellos mismos logren salir de la situación en que se encuentran y, de esta manera, puedan contribuir también al bien del todo social, desde su particular condición (Satriano, 2006). No hacerlo, afecta de manera significativa el bien común, cuya consecución pasa de manera obligada por la realización efectiva de la justicia general, tal como se muestra en las líneas que siguen.

\section{Política social y JUSTicia GENERAL}

La adecuada intelección de la relación existente entre las partes y el todo, constituye un aspecto esencial para la vida en sociedad. Según afirma Gabriel Chalmeta, hay una relación inescindible que vincula a la sociedad política con la vida de cada ciudadano: el vivir bien, que es cabalmente la cuestión central de la que se ocupa la ética, depende en buena parte de cómo se configure el futuro 
sistema de relaciones políticas (Chalmeta, $2000)^{1}$. Esta relación conforma un determinado tipo de orden social que exige, por una parte, que cada uno de los miembros de la sociedad reciba del Estado la ayuda necesaria para "realizar una existencia perfecta, de manera que no solo pueda subsistir, sino también vivir bien" (Aquino, 2001a, prólogo); y, por otra, que los miembros de la comunidad política ordenen sus cosas respecto del todo y del fin que ella persigue, es decir, el bien común, que es el bien de todos. Por eso, el orden social es uno de los elementos que, esencialmente, integran el bien común. Este tipo de orden no es hecho o construido por la razón, sino que ella lo ha de considerar porque está en la naturaleza misma del hombre que es social: cada hombre está inclinado y dirigido objetivamente a una serie de comportamientos habituales que, aunque perteneciendo a especies muy diversas, son todos referibles al bien común, esto es, a la justicia general (Aquino, 2001b, $\mathrm{V}$, lecciones 2-3).

\footnotetext{
Esta realidad ha sido puesta en tela de juicio por algunos sectores académicos que afirman que las relaciones sociales deben estar ordenadas según una serie de principios de justicia política, en donde no haya una concepción ética específica de los ciudadanos. En esta línea de pensamiento, John Rawls (1997) afirma que la libertad equitativa, principio básico de una sociedad "bien ordenada", implica que nadie puede obligar a otro a tener determinada comprensión de los primeros principios morales. Hacerlo, implica poner al otro en una libertad inferior e incurrir en el irrespeto por su igual libertad de consciencia (p. 202). El argumento de Rawls, que recoge de un amplio sector de la Modernidad, se basa en que en la sociedad pluralista moderna no es posible la unidad de visiones éticas. No obstante, de manera contradictoria, a la par que se propugna por la neutralidad ética y la libertad, se trabaja de manera incansable por establecer principios normativos comunes que regulen la convivencia y hagan viable la vida social. Lo cierto es que el resultado de esta ausencia de comprensión común de principios éticos básicos, ha traído como consecuencia histórica el que, lejos de resolverse los conflictos sociales existentes y alcanzar el orden social, estos se han hecho más agudos haciéndose inviable el orden social.
}

Lo anterior implica un reconocimiento y afirmación de la libertad humana que permite que el querer y el obrar de unos se conjugue con el querer y el obrar de los otros para construir el bien de todos. Sin libre albedrío, el ciudadano no podría trabajar en su crecimiento personal, que es base para la construcción del bien común. Como afirma Gabriel Chalmeta (2000), "no se puede hacer virtuoso a un ciudadano al margen de su libertad, pensarlo sería utilitarismo puro" (p. 123). En otras palabras, el que existan personas en situación de marginación social y económica es una afrenta al bien del todo social, no solamente desde la perspectiva de la justicia distributiva, sino desde la óptica de la justicia general, en razón de que habrá personas que, por su condición, encuentran limitaciones importantes para cumplir con su obligación de contribuir a la preservación de la comunidad política.

Así pues, el orden social, que es un valor de coexistencia social, un bien común, exige la obligación de respeto y promoción del otro, como algo que no es extraño al bien del sujeto mismo. Por eso, la realización efectiva de la justicia exige de cada miembro de la colectividad obrar en armonía con preceptos positivos generales como el de contribuir al bien del todo social, para lo que se precisa que cada ciudadano aporte según su condición y capacidad. De allí que no sea legítimo invocar la defensa de la libertad como vía para eludir la obligación que cada ciudadano tiene de contribuir positivamente al bien común; todo lo contrario, es desde su libertad -una libertad auténtica- que cada persona está llamada a hacer lo posible para promover dicho bien.

Esta es una de las premisas sobre las que se ha de estructurar la política social en 
el Estado, si se quiere tener éxito en ella y configurar de manera adecuada el tejido social. Las transferencias en forma de recursos financieros y de servicios en materia de salud, educación, seguridad social, vivienda, protección laboral, etc., que tienen lugar en desarrollo de las políticas sociales, y que implican una acción positiva por parte del Estado respecto de personas o grupos poblacionales que por diversas condiciones económicas, sociales y políticas, se encuentran en situaciones que demandan la ayuda solidaria de este, encuentran su fundamento en la propia condición humana y su naturaleza social, y adquieren mayor valía cuando ellas buscan solucionar exageradas desigualdades materiales (Fraser, 1997). Empero, conviene tener presente que la política social tiene una doble dinámica. Por un lado, la que refiere a la intervención para materializar los derechos y mejorar la calidad de vida de los miembros de la comunidad políticamente organizada, en aras de garantizar la igualdad frente a lo que se tiene que ser igual: la necesidad de tener lo suficiente para vivir con dignidad ${ }^{2}$; por otro lado, la atinente al cuidado que se ha de tener para no convertirla en un instrumento para el asistencialismo y el clientelismo que lleva a que los destinatarios, en lugar de

2 Para ello, se reparten recursos para eliminar o reducir sustancialmente las desventajas de los menos favorecidos en la sociedad en donde se atiende a necesidades e intereses, lo cual está frecuentemente relacionado con las exigencias de igualdad. Este tipo de igualdad es llamada por Amartya Sen (1982): "igualdad de capacidad básica" (p. 368). Sobre ella indica: "En primer lugar, no afirmo que la igualdad de la capacidad básica sea la única guía del bien moral. La moralidad, para empezar, no se ocupa solo de la igualdad. Por otra parte, si bien sí afirmo que la igualdad de la capacidad básica tiene ciertas ventajas claras sobre otros tipos de igualdad, no creo que los otros sean moralmente irrelevantes. La igualdad de la capacidad básica es una guía parcial de la porción del bien moral que se ocupa de la igualdad. He intentado demostrar que como guía parcial tiene sus virtudes que no poseen otras caracterizaciones de la libertad. (Sen, 1982, citado en Urquijo, 2014). superar las desigualdades, mejorar su calidad de vida y convertirse en actores sociales fuertes y autónomos, terminen consumidos en su situación de marginación y pobreza. Desde dicha situación se imposibilita su contribución al bien común.

Cuando las políticas sociales que se desarrollan en el Estado -que de buena fe buscan compensar a los marginados por cuenta de una injusticia social estructural-, conducen a desatender por parte de sus destinatarios esa obligación de aportar al bien de todos en el efectivo empeño de cada uno por promover el bien común por medio del trabajo, de la disposición para educarse, del pago de bienes y servicios en la medida de las propias capacidades, etc., el resultado es la afectación del orden social: allí las cosas no están en su lugar porque las personas no hacen lo que les corresponde en aras de contribuir al mejoramiento de toda la comunidad a la que pertenecen ${ }^{3}$.

La realización del ser humano no se da solamente en una orientación hacia sí mismo propter se-, sino que se da fundamentalmente cuando, como producto de su libertad, decide ordenarse al bien de la comunidad -propter aliud- (Chalmeta, 2000). Lo bueno para el hombre no se encuentra desvinculado de características colectivas, sino que, por el contrario, implica una apertura a la comunidad política, lo que a su vez conlleva la valoración de logros sociales o colectivos

3 A nivel de política social, es más importante para una nación asegurar altos índices de empleo que adelantar programas de asistencia social sin medida. Según Joseph Stiglitz (2012), los índices de desempleo incrementan las desigualdades sociales. En este sentido afirma: "Y dado que los más ricos gastan una menor proporción de sus ingresos que los de abajo -a los que les no les queda más remedio que gastárselo todo-, la desigualdad da lugar a un debilitamiento de la economía. Se produce un círculo vicioso descendente. Y la austeridad exacerba todo. (Prólogo a la edición española). 
de naturaleza ética (Aguilar Villanueva, 2012). Allí, la integración del individuo en el todo se convierte en un enriquecimiento personal y no en una degradación a la que sí lleva el eximirle de aportar al bien de toda la sociedad, como sucede con una política social compensatoria que hunde en la pobreza y en la marginación social, en lugar de ayudar a salir de ellas.

Como lo ha analizado Carlos Cossio (1964), el orden ayuda al afianzamiento de la seguridad, que es otro de los valores esenciales para la coexistencia humana. El excesivo ejercicio de una autonomía mal entendida a la que conduce una sociedad permeada por el individualismo, deviene en inseguridad. El orden social es un valor de heteronomía que hace posible la convivencia social en la medida en que cada integrante de la misma, desde su particular condición, haga lo que le corresponde para contribuir a la coexistencia social; $y$, si es valor de heteronomía, significa que es dado al sujeto como un imperativo externo que es límite y medida para el simple querer autónomo: "en el orden mi heteronomía es también la heteronomía del otro" (Ynoub, 2007, p. 201).

El orden social, así entendido, es el resultado de la armonía social. No del mero equilibrio social en donde varias fuerzas confluyen para anularse, sino del actuar armónico que permite alcanzar la unidad en la diversidad. Con la armonía se logra un "género particular de orden que consiste en que las diferentes partes o funciones de un ser no se oponen, sino que concurren a un mismo efecto de conjunto" (Thibon, 1978, p. 14). En el actuar armónico con el otro, lo que cuenta no es la cantidad, el peso y la relación de fuerza, sino la convergencia de las voluntades de las personas hacia un fin que se comparte. La armonía implica reconocimiento de la diferencia y superación de las desigualdades mediante el diálogo y el acuerdo, en función de un fin común ${ }^{4}$.

Hablar de justicia es referir a una realidad relacional. Por eso, el acto de justicia tiene lugar en el marco de una relación de justicia, esto es, en el encuentro de dos o más sujetos en razón de sus respectivos derechos. Por eso, la relación de justicia es intersubjetiva, lo que significa que por lo menos hay dos sujetos en distinta y complementaria posición: el acreedor y el deudor. Se trata, por lo tanto, de una relación alteritiva que comprende tres elementos esenciales: los sujetos, el vínculo jurídico y el contenido de la relación.

En la relación de justicia llamada "justicia general", se mira lo que debe el individuo a la comunidad políticamente organizada, esto es, al Estado. Esto significa que los sujetos de la relación son las personas que hacen parte de la comunidad -en calidad de deudores- y el Estado -en calidad de acreedor-. Por justicia general, entonces, cada uno debe aportar al Estado según su condición y sus capacidades.

El fundamento de la relación de justicia está en la propia condición humana. Bilbao (1996), citando a Aristóteles, pone de presente cómo la definición del ser humano implica el considerar su realidad social y su

4 Afirma Gustave Thibon (1978), que hoy se habla de igualdad dejando de lado "[...] la distinción entre equilibrio y armonía: es un principio basado en la ley del número (cantidad) y no deja sitio más que para relaciones de fuerza entre individuos que no tienen ningún lazo que los una. Surge entonces el conflicto que se erige como ley permanente a nivel social en el que la fuerza es el medio para hacerse oír: desequilibrios en cadena que intentan ser solucionados por medio de concesiones y compromisos que están llenos, a su vez, de nuevos desórdenes porque están basados en la injusticia: dan cosas a quienes no tienen el derecho de tenerlas con tal de superar la crisis. Son medios provisionales y superficiales". (Pp. 14-15). 
ser parte de la sociedad política, no como un añadido, sino como algo propio de su ser, en donde cada individuo cumple una finalidad. El hombre no es entendido como una abstracta representación, a la que se le agregan sucesivos atributos, sino que se entiende en su efectiva configuración que incluye la existencia de los otros. El pensamiento y el habla, facultades superiores de la persona, solo son tales en su efectiva relación con otros individuos. De este modo, la naturaleza del individuo es inescindible de sus relaciones sociales. La comunidad políticamente organizada -el Estado- es el lugar de la realización del individuo y, en cuanto miembro de ella, debe aportar a su crecimiento y estabilidad.

¿Cuál es el derecho que le corresponde al Estado y cuya realización puede ser exigida a quienes lo integran? Desde la tradición clásica se ha considerado que dicho derecho se llama bien común y todos los asociados están llamados a contribuir a su consecución (Hervada, 2000) ${ }^{5}$. Es por ello que la justicia general y el bien común han sido considerados, históricamente, como dos realidades inescindibles. A la realización efectiva de la relación de justicia general se le llama bien común. Ahora bien, aunque la noción de bien es simple y primaria $\mathrm{y}$, por lo tanto, propiamente hablando, no admite una definición, es necesario examinar la realidad a la que refiere el expresar que algo es bueno o está bien, y aquella que se indica cuando se afirma que eso que es bueno, es común.

5 En el entendido de que la ley es justa, la filosofía clásica consideró que la mejor manera de aportar al logro del bien común era mediante el cumplimiento de las leyes, por eso, a la justicia general se le dio el nombre de justicia legal; en ella el acto de justicia se mide por el cumplimiento de lo mandado por la ley (Hervada, 2000, p. 38).
Cuando se habla de que algo es bueno, es lugar común aceptar que con ello se hace alusión a su efecto de conservación. En razón de esto, la voluntad humana lo desea porque el ser humano se inclina hacia aquello que le parece bueno (Aquino, 2001b, I, $5,1 c)$. Lo anterior significa que el bien para una comunidad politicamente organizada es lo que la preserva (Aristóteles, 2000, libro I, cap. II). Cuando aquello que preserva se extiende a cada uno de los que integran la sociedad, entonces, se está frente al bien común, también llamado "bien de todos". Es un tipo de bien que, a la vez que no está en contraposición del bien individual, lo supera porque es el resultado del trabajo cooperativo entre las personas: cada uno debe contribuir al bien de todos, el cual constituye un fin común para aquellos que, por naturaleza, son diferentes, tal como acontece con la realidad personal del ser humano (Cardona, 1966) ${ }^{6}$.

Se trata de conjugar, de armonizar las voluntades hacia un telos común, hacia un

6 "Con directa referencia al caso de la comunidad humana, Santo Tomás enuncia y razona una verdad que es aplicable a la totalidad de los seres creados: 'el que persigue el bien común de la multitud, en consecuencia persigue también su bien (el de él), por dos razones. Primero, porque el bien propio no puede darse sin el bien común, ya de la familia, ya de la ciudad o del reino. Por lo que Máximo Valerio dice de los antiguos romanos que <preferían ser pobres en un imperio rico, que ricos en un imperio pobre>. En segundo lugar, porque como quiera que el hombre sea parte de la casa y de la ciudad, conviene que el hombre considere el bien que se le sigue de ser prudente en relación con el bien de la multitud: pues la buena disposición de la parte se establece por su relación al todo, porque, como dice San Agustín en el libro Confesiones, 'es torpe la parte no congruente con el todo" (Aquino, 2001b, II-II, 47, 10 ad 2). Dos razones, pues, muestran que al buscar el bien común se busca necesaria y consecuentemente el propio bien: [1] por el beneficio que la parte recibe del todo - podríamos llamar a esto la redistribución la reversión del todo hacia la parte-; y [2] porque la parte se debe al todo - podríamos llamar a esto la integración de la parte en el todo-, de tal manera que no puede ser todo lo que debe ser, no puede alcanzar su propio fin sino en relación con el todo" (Cardona, 1966, p. 59). 
fin compartido por todos (Millán, 1973). En esta misma línea de pensamiento, señala MacIntyre (2001) que todo ser humano tiene la tarea de preguntarse cómo puede contribuir al bien de los otros, pues los individuos logran su propio bien solo en la medida en que los demás hacen de ese bien un bien suyo. Tanto mayor es el bien cuando lo es para más seres, esto es, cuando es común; y ello implica la participación de todos y cada uno de los miembros de la colectividad (Cardona, 1966).

En razón de lo anterior, históricamente se ha establecido una necesidad de subordinación de cada miembro de la colectividad al bien común. Ello no implica, en absoluto, la negación de la propia libertad, sino su plenificación, toda vez que dicha subordinación no es desublimación de la persona, sino elevación de la misma. La libertad y autonomía del individuo es una condición que se realiza solamente en el cumplimiento de las determinaciones de un orden ajeno y exterior a él (Bilbao, 1996).

Subordinarse al bien común es -afirma Millán (1973)-, realmente, elevarse, romper las ataduras que al ligarnos al bien particular impiden que este se integre en el de todos, que es objetivamente un bien más alto. Porque, efectivamente, un bien es tanto más bueno y valioso cuanto mayor es el número de seres a los que puede beneficiar, lo mismo que una luz es tanto más intensa cuanto más grande es el número de seres a los que puede iluminar. De aquí que el solo querer el puro y simple bien particular sea objetivamente una degradación, un verdadero rebajamiento de una voluntad que, por naturaleza, está capacitada para un bien superior y mucho más intenso. $Y$ en lo que atañe a la dignidad "moral" de la persona humana, no se ve que el querer el bien común sea, por ciento, lo indigno moralmente, a menos que se confunda la dignidad moral y el egoísmo, y no se acierte a ver que el querer y procurar el bien de todos es magnanimidad y no bajeza.

Corolario de lo anterior es que el que las personas no contribuyan al bien común, constituye un principio de desintegración de la sociedad por la afectación de los valores de coexistencia que dicho bien encierra. Por eso, la realizacion de la justicia general exige de todos contribuir para que los valores de coexistencia social, necesarios para que sea viable la vida personal y comunitaria, tengan lugar en el Estado. Cuando la actividad desplegada por un particular -así esté siendo promovida y avalada por el Estado mismo como acontece con la política social compensatoria- no contribuye al bien común, se configura una forma de injusticia general que da lugar a diversas formas de violencia social.

Lo referido en las líneas precedentes, permite ver cómo el bien humano no es solo individual, sino que tiene naturaleza común, de manera que la vida en sociedad es un bien común en sí mismo, al punto que el vivir bien individual solamente es posible en el marco de un vivir bien junto a los otros (Aquino, 2010, I, 1). El ser humano tiene una vocación que lo invita a vivir en verdadera amistad con el otro, en una relación de reciprocidad y respeto, lo cual solo es posible en la medida en que se busquen y compartan valores en medio de las diferencias que son propias de la realidad personal de cada uno. Por eso, la realización de esa vocación posibilita la unidad de la paz: "El fin al que debe sobre todo mirar la persona que rige 
una comunidad política es la realización de la unidad de la paz" (Aquino, 2010, I, 3).

La unidad de la paz solamente es posible cuando hay justicia, es decir, cuando los derechos de las personas que integran el todo social se ven efectivamente realizados. Ello, por cuanto la injusticia es la principal fuente de discordias y divisiones al interior de una sociedad políticamente organizada (Aristóteles, 2000, L. V). La paz demanda de cada miembro de la sociedad que su libertad se conjugue con la libertad de los otros para elegir lo mejor y realizar acciones positivas que afiancen los vínculos de unidad con los otros (Guarín, 2016).

La política social, tal como se advirtió al inicio de este artículo, tiene una doble dinámica y, por lo tanto, si bien debe producir el bien material de los asociados, no menos tiene que evidenciar el que esté contribuyendo realmente al crecimiento de las personas y a la superación de su situación de marginación social. Si dicha política consume a sus destinatarios en la pobreza y la marginalidad, genera brechas sociales que rompen los vínculos de unidad que se precisan para la consecución de la convivencia pacífica. La política social de tipo asistencialista no es, por lo tanto, un medio idóneo para garantizar ese bien común político a través de la convivencia pacífica porque no ejerce, realmente, un influjo benéfico en los usos y costumbres sociales que permitan evitar o superar los conflictos, que son unos de los responsables de la disolución del orden social, lo cual es contrario a la justicia general, vía para la consecución del bien común.

En la base de estas consideraciones en torno a la relación individuo-Estado, hay una antropología que concibe la sociedad como un hecho específicamente humano en donde se conjugan naturaleza y libertad. En efecto, la sociedad es la es el resultado de la condición social propia del ser humano y del despliegue de la libertad de las personas que la integran. Es una,

\section{[...] asociación necesaria que se vive y} se realiza libremente. El fundamento natural de la sociedad es la incapacidad que tiene el hombre para realizar su fin específico en solitario. El hombre, para satisfacer sus necesidades espirituales y materiales, necesita la colaboración de otros hombres. Solo así puede alcanzar la felicidad a la que su naturaleza le llama. (Díez-Antoñanzas, 1996, p. 206).

En esa colaboración se crean vínculos de unidad que son la fuente de la paz.

Lo anterior no significa, en modo alguno, la consideración de que la persona es para la sociedad en el entendido de que lo social lleve a una reducción de la persona a ser simplemente una parte de la comunidad. Esa postura extrema ya ha mostrado su fracaso histórico. La consideración de que lo social es fuente de unas exigencias de comportamiento respecto de la comunidad a la cual se pertenece, se desprende la misma naturaleza humana que necesita de los otros para alcanzar su plenitud, sin que, por ello, sea legítimo aseverar que la persona pierde su individualidad cuando entra a formar parte del todo social $y$, por ende, deja de construir su propia historia y biografía desde su actuar libre.

De conformidad con lo dicho en las líneas precedentes, es posible afirmar que la relación de justicia general es una importante fuente de convivencia pacífica al interior de 
la sociedad, por cuanto ella exige, por una parte, el respeto por la primacía de la persona y, por otra, la ayuda mutua entre los miembros de la comunidad políticamente organizada para alcanzar el bien común, que es su fin específico.

El Estado no es más que un instrumento para cumplir el fin propio de la sociedad. Teniendo, pues, en cuenta que la dignidad de la persona exige que sea ella la que realice, en la medida de lo posible, su fin propio, se comprende bien que el Estado no debe realizar nada que los ciudadanos puedan hacer por sí mismos; $y$, por otra parte, deberá ayudar a que efectivamente estén en condiciones de hacerlo, de modo que, muy excepcionalmente, el Estado deba suplirlos en esas funciones. (Díez-Antoñanzas, 1996).

Estas premisas son fundamentales para la construcción de una comunidad que viva en paz, a lo cual no contribuye una política social que perpetúa en la marginalidad y en la pobreza.

Esta manera de concebir las relaciones entre los particulares y el Estado en nada afecta la solidaridad social, sino que, por el contrario, ayuda a su realización. En efecto, la solidaridad hunde sus raíces en la apertura natural del hombre a los demás hombres, razón por la cual es una exigencia de su propia dignidad, excelencia o bondad personal (Herrera, 2016). Atendiendo a esta característica de ese "hacer propia la suerte del otro" y estar presto a ayudarle y a hacerse uno con él, que es nota esencial del actuar solidario (Vitoria, 1974, p. 5), la Corte Constitucional colombiana ha puesto de presente en varias providencias que la solidaridad se plantea como derecho que proviene de la pertenencia al conglomerado social, pero también como un deber que es exigible, tanto para el Estado como para los asociados. (Pueden verse las Sentencias T-413 del 2013, T-225 del 2005 y T- 608 del 2015, entre otras).

En cuanto derecho, la solidaridad implica la facultad que tienen los asociados de exigir al Estado que haga suya su suerte cuando, por diversos factores, la requiere; en cuanto tal, la solidaridad es debida por el Estado y exigible por los ciudadanos como verdadero derecho (Guarín-Ramírez y Rojas-Claros, 2018). En cuanto deber, exigible no solamente al Estado sino a los asociados, la solidaridad implica que todos los miembros de la sociedad política están llamados a contribuir a la configuración de un cuerpo sólido -el Estado-, en el que hay compromiso u obligación en un vínculo de participación y reciprocidad en una comunidad (Razeto, 2005). Sobre este aspecto de la solidaridad poco se insiste hoy, pero está a la base de una adecuada concepción de la misma porque la solidaridad tiene fundamento en el hecho de que los seres humanos se encuentran dentro de un orden que trasciende la propia individualidad que exige lo que Javier Hervada (2014) llama la conspiratio o unión armónica de los hombres, sin la cual es inviable la vida humana personal y social.

La solidaridad tiene como premisa básica el que todos los seres humanos somos sociables por naturaleza, miembros de un gran cuerpo y que debemos ayudar a su buen funcionamiento en el marco de una relación de amistad (Beltrán Serra, 2008). Por eso, ella implica el deber de los asociados de contribuir a la preservación de la comunidad política, para lo cual tienen 
la obligación de velar por su autocuidado y el desarrollo de capacidades que les permitan lograr, por sí mismos, la satisfacción de sus propias aspiraciones y proyectos de vida (Sentencia T-608, 2015). La solidaridad, por tanto, plantea a cada ciudadano algunas exigencias que, si no son respetadas, pueden justificar, incluso, que se considere a una política social o a un ordenamiento jurídico como injusto (Massini, 2006).

La cuestión del desarrollo, ahora enunciado con los calificativos de humano y social, solo es posible en la medida en que, realmente, cada uno de quienes integran el núcleo social, contribuya a la construcción de relaciones sociales que conduzcan al bien con la participación de todos, esto es, relaciones solidarias (Aldana, 2007). Estas relaciones solidarias que posibilitan el desarrollo humano implican una respuesta ética al problema de la pobreza de quienes, incluso trabajando, no alcanzan a tener las condiciones materiales suficientes para vivir (Peces Barba, 1991). Por eso, las políticas sociales direccionadas en este sentido son importantes para hacer frente a situaciones de marginación social, cuya atención constituye un valioso aporte para la consecución de la justicia y el bien común (Beltrán Serra, 2008). Pero el desarrollo fundamentado en relaciones solidarias también implica el que cada asociado se haga uno (in solidum) con su comunidad política, creando una comunidad axiológica en donde existen vínculos de fraternidad: un afecto que une y dirige hacia un objetivo común que es el bien de todos (Bloch, 1980).

El problema de las políticas sociales compensatorias no radica en el bien que con ellas se hace, sino en que no están contribuyendo al mejoramiento de las capacidades de los individuos para realizarse en diferentes vías, en diferentes dimensiones de la vida personal y de la interacción social. Estas políticas, que terminan siendo asistencialistas $\mathrm{y}$ no asistenciales porque han perdido su naturaleza subsidiaria, se han convertido en una fuente de inequidad en la distribución de recursos públicos, a lo que se suma el que no dan suficientes oportunidades a las personas para que puedan configurar su propio destino. Consecuencia de esto es que la política social compensatoria termina multiplicando programas a la par que reduce las posibilidades de un verdadero crecimiento de la población beneficiaria, que queda atrapada en una estructura altamente dependiente del Estado (Satriano, 2006). Allí, la solidaridad que se exige como deber de la persona frente a la comunidad, desaparece y, con ello, un importante factor de cohesión social (Román Brugnoli y Osorio Gonnet, 2015). Y, dado que la justicia general ordena la conducta de los individuos a la "vida buena social en su integralidad, que exige a todos los asociados aportar todas sus perfecciones y virtudes" (Cárdenas y Guarín, 2010, p. 54), al no existir tal aportación, surge una forma de injusticia en el seno de la sociedad.

De contera, dado que la política tiene como finalidad el bien común y no el bien de uno o unos pocos, las políticas compensatorias, desarrolladas en la forma como se está haciendo en Colombia, tienen en realidad poco o nada de verdadera política e, incluso, su carácter compensatorio puede ser duramente cuestionado, dado que, como se mencionó en la primera parte de este escrito, no en pocas ocasiones se dirige a personas distintas de quienes son sus verdaderos 
destinatarios: aquellos que han sufrido la pobreza y la marginación social, y lo más preocupante es que es muy probable que los problemas materiales de la precariedad de la vida de poblaciones o grupos sociales, jamás se resuelvan si al mismo tiempo no se neutralizan y sancionan las trasgresiones de los valores fundamentales de la vida en común y de la equidad de trato entre los ciudadanos (Aguilar Villanueva, 2012).

\section{Conclusiones}

Desde la perspectiva axiológica desarrollada a lo largo de este artículo, la justicia general posibilita un mejor entendimiento societario. Las acciones injustas socavan el entendimiento y el encuentro con el otro en el marco de alteridad. Vivir con el otro implica entenderse y actuar de manera coordinada con él, especialmente a través de la vivencia de los valores comunitarios que han sido desarrollados a lo largo de estas líneas. Por ende, si alguno de los valores enunciados: el orden, la paz y la solidaridad -entre otros que podrían haberse estudiado-, se ven afectados por algún motivo -en este caso por la política social compensatoria con las características que tiene actualmente en Colombia-, emerge la injusticia y, con ella, la desconfiguración de la vida social. La justicia general abre la posibilidad para que los conciudadanos dialoguen, compartan, asuman sus deberes como miembros de la comunidad y, de esta manera, construyan juntos mejores formas de coexistencia (Cossio, 1964).

La política social de un Estado, además de entregar subsidiariamente bienes y servicios a los ciudadanos que realmente los necesiten, ha de favorecer, esencialmente, la buena educación que prepara a las personas para que, con su trabajo y el desarrollo de sus potencialidades, aporten a la preservación del bien común. La unidad de la paz, el orden y la solidaridad que permiten alcanzar el bien material y espiritual de las personas que integran la comunidad política, se logran si existen relaciones de justicia efectivas en las que se respeten, tanto los derechos de las personas, como aquellos que le pertenecen al todo social. La política social compensatoria, tal como se lleva a cabo actualmente en Colombia, no está contribuyendo al bien común, según se ha analizado a lo largo de este escrito. Antes bien, un alto porcentaje de los programas que se adelantan en virtud de dicha política social, hacen que la marginación social se vuelva más atractiva, pues entregan dineros y subsidios que ayudan a suplir necesidades básicas con poco esfuerzo o, incluso, sin necesidad de él. El no estimular el esfuerzo de las personas conduce a que, quien tiene carencia de bienes materiales, ya no vea la necesidad de emprender acciones que le posibiliten superar su situación y otros, que ven en esa manera de actuar por parte del Estado beneficios, hacen todo lo posible para entrar en esa dinámica social, convirtiendo los programas, no el algo subsidiario como tiene que ser, sino en un modus operandi permanente y progresivo (Isuani y Tenti, 1989). Con ello se afecta, no solo la propia condición personal del ser humano que no se reduce a lo material, sino la vida social que necesita el aporte de todos para poder ser viable, tal como se mostró a lo largo de este artículo.

El bien común no está en las manos de una sola persona; es una tarea de todos y cada uno debe trabajar por él, no como cosa ajena, sino como, en realidad lo es, un bien propio. 
Como lo señala John Rawls (1997), la justicia social exige, ante todo, una justa igualdad de oportunidades que les permita a las personas estar capacitadas para crecer en su vida individual y para que, a partir de ello, puedan contribuir de manera efectiva a la consolidación de valores comunitarios que posibiliten a cada persona alcanzar la felicidad.

\section{REFERENCIAS}

Aguilar Villanueva, L. (2012). Política pública. México D. F., México: Siglo Veintiuno Editores.

Aldana, O. U. (2007). Desarrollo, ciudadanía y cambio. (O. Useche, M. Naranjo, y L. Cabrera, eds.) Bogotá D. C, Colombia: Ediciones Antropos Ltda.

Alvarado-Chacín, N. (2003). Pobreza y asistencialismo en Venezuela. Revista de Ciencias Sociales, 432-453.

ANIF, Clavijo, S. y Londoño, D. (14 de junio del 2017). La lucha contra la pobreza y el problema del Sisbén. Recuperado de http://www.anif.co/Biblioteca/politica-fiscal/la-lucha-contra-la-pobreza-yel-problema-del-sisben

Aquino, T. d. (2001a). Comentario a la Ética a Nicómaco de Aristóteles. Pamplona, España: Eunsa.

Aquino, T. d. (2001b). Suma Teológica. Madrid, España: BAC, edición digital.

Aquino, T. d. (2010). De Regno. Barcelona, España: BAC.

Aristóteles. (2000). La Política. Bogotá D. C., Colombia: Panamericana.

Beltrán Serra, J. (2008). La amistad y el amor en el epistolario de Séneca. Cuadernos de Filología Clásica. Estudios Latinos, 28(1), 17-41. Recuperado de http://revistas. ucm.es/index.php/CFCL/article/view/ CFCL0808120017A
Bilbao, A. (1996). Aristóteles y Smith: la política y la ciencia. Revistas UCM, 73-87.

Bloch, E. (1980). Derecho Natural y dignidad humana. Madrid, España: Aguilar.

Cárdenas, C. y Guarín, É. (2010). Las formas de justicia. Bogotá D. C., Colombia: Universidad Santo Tomás.

Cardona, C. (1966). Metafísica del bien común. Madrid, España: RIALP.

Casas Ortiz, F. (16 de diciembre del 2014). ¿Qué genera el asistencialismo? La Nación. La noticia independiente. Recuperado de https:// www.lanacion.com.co/2014/12/16/ que-genera-el-asistencialismo/

Chalmeta, G. (2000). La justicia política en Tomás de Aquino. Pamplona, España: Eunsa.

Corte Constitucional de Colombia. (2005). Sentencia T-225, Corte Constitucional colombiana.

Corte Constitucional de Colombia. (2013). Sentencia T-413, Corte Constitucional colombiana.

Corte Constitucional de Colombia. (2015). Sentencia T-608, Corte Constitucional colombiana.

Cortés, C. (17 de junio del 2010). Familias en Acción: más subsidios, más votos. $\mathrm{La}$ Silla Vacía. Recuperado de http://lasillavacia.com/historia/16024

Cossio, C. (1964). Teoría egológica del derecho (y el concepto jurídico de la libertad). Buenos Aires, Argentina: Abeledo Perrot.

Díez-Antoñanzas, P. (1996). Hombre y sociedad: una introducción al pensamiento politico de Antonio Millán Puelles. Pamplona, España: Eunsa.

Departamento Nacional de Planeación -DPN-. (Octubre del 2016). La Dirección Nacional de Planeación alerta por nuevos 'colados' en el Sisbén que ganan más 
de \$3.8 millones al mes. Recuperado de https://www.dnp.gov.co/Paginas/ DNP-alerta-por-nuevos-\%E2\%80\%98colados\%E2\%80\%99-en-el-Sisb\%C3\%A9n.aspx

Departamento Nacional de Planeación -DPN-. (2017). Pobreza Monetaria y Multidimensional en Colombia 2017. Recuperado de https://www.dane.gov.co/index.php/ estadisticas-por-tema/pobreza-y-condiciones-de-vida/pobreza-y-desigualdad/ pobreza-monetaria-y-multidimensional-en-colombia-2017

Franco Martínez, P. (2011). Análisis de las críticas sobre asistencialismo estatal en la lucha contra la pobreza durante la presidencia de Álvaro Uribe Vélez (2002-2010), a través del programa Familias en Acción. Bogotá D. C., Colombia: Universidad Colegio Mayor de Nuestra Señora del Rosario.

Fraser, N. (1997). Iustitia Interrupta. Reflexiones críticas desde la posición postsocialista. Bogotá D. C., Colombia: Siglo del Hombre - Universidad de los Andes.

González Bonilla, R. (2006). Pobreza, estructura de propiedad y distribución del ingreso. En A. Rodríguez Castillo, V. Gómez Campo, I. Jaramillo Pérez, A. Machado Cartagena, G. Misas Arango, R. Bonilla González, ... D. Restrepo Botero, Politicas públicas para Colombia (pp. 103-122). Bogotá D. C., Colombia: Friedrich Ebert Stiftung en Colombia.

Guarín, É. (2016). La libertad de los jueces para fallar en positivo. Bogotá D. C., Colombia: USTA- Ibáñez.

Guarín-Ramírez, É.-A. y Rojas-Claros, A. (2018). La medida de la solidaridad: responsabilidad del Estado y derecho de los asociados. Bogotá D. C., Colombia: Universidad Católica de Colombia.

Herrera, C. (2016). Aproximación a los fundamentos filosóficos y científicos del iusnaturalismo realista de Javier Hervada. Pamplona, España: Eunsa.

Hervada, J. (2000). Introducción crítica al derecho natural. Bogotá D. C., Colombia: Temis-Universidad de la Sabana.

Hervada, J. (2014). El ordo universalis como fundamento de una concepción cristiana del derecho y otros escritos de juventud. Pamplona, España: Eunsa.

Huertas, L. A. (17 de marzo del 2018). El problema del asistencialismo. El olfato. Recuperado de https://www.elolfato. com/el-problema-del-asistencialismo/

Isuani, E. y Tenti. (1989). Estado democrático y política social. Buenos Aires, Argentina: Eudeba.

MacIntyre, A. (2001 ). Tras la virtud. Barcelona, España: Crítica.

Massini, C. (2006). La prudencia jurídica. Buenos Aires, Argentina: Abeledo Perrot.

Millán, A. (1973). Persona humana y justicia social. Madrid, España: RIALP.

Muñoz, A. (17 de abril del 2005). El asistencialismo crea más pobreza, sostiene la OCDE. La Jornada. Recuperado de http:// www.jornada.com.mx/2005/04/17/ index.php?section $=$ politica \&arti cle $=021 n 1$ pol

Peces Barba, G. (1991). Humanitarismo y solidaridad social como valores de una sociedad avanzada. Las entidades no lucrativas de carácter social y humanitario. La Ley. Recuperado de http://e-archivo.uc3m.es/bitstream/ handle/10016/16005/humanitarismo_ Peces_1991.pdf?sequence $=1$ 
Rawls, J. (1997). Teoría de la justicia. México D. F., México: Fondo de Cultura Económica.

Razeto, L. (2005). Conceptos fundamentales Vol. III. Pensamiento crítico latinoamericano, 971-985.

Román Brugnoli, J., y Osorio Gonnet, C. (2015). Solidaridad y políticas públicas en el discurso de los Gobiernos de la Concertación. Revista Electrónica de Psicología Politica, (35). Recuperado de http://www.psicopol.unsl.edu. ar/2015-Diciembre-03.pdf

Ronderos, M. (3 de marzo del 2010). ¿Por qué Colombia no sale del club de los pobres? Semana. Recuperado de https:// www.semana.com/nacion/articulo/ por-que-colombia-no-sale-del-club-pobres/114313-3

Rubin, S. (22 de julio del 2018). Diálogos a fondo: Padre Opeka: “A los pobres hay que ayudarlos con trabajo. El asistencialismo solo genera dependencia". El Clarin. Recuperado de https://www.clarin. com/opinion/xxx_0_S1ti0V677.html
Satriano, C. (Septiembre del 2006). Pobreza, políticas públicas y políticas sociales. Revista Mad., (15), 1-7. Recuperado de http://www.facso.uchile.cl/publicaciones/mad/15/satriano.pdf

Sen, A. (1982). Choice, Welfare and measurement. Oxford, Reino Unido: Blackwell.

Stiglitz, J. (2012). El precio de la desigualdad. El $1 \%$ de la población tiene lo que el $99 \%$ necesita. Barcelona, España: Taurus.

Thibon, G. (1978). El equilibrio y la armonía. Madrid, España: Rialp.

Urquijo, M. (2014). La teoría de las capacidades en Amartya Sen. EDETANIA(46), 63-80.

Vitoria, F. d. (1974). De la potestad civil. México D. F., México: Porrúa.

Ynoub, R. (2007). La axiología jurídica de Carlos Cossio: revisión teórica para la adaptación a categorías descriptivas de la psicogénesis de la experiencia normativa. Universidad de Buenos Aires (ed.). XVI Jornadas de investigación y tercer encuentro de investigadores en psicología del Mercosur, pp. 200-204. 